\title{
Iron Pincer Complexes as Catalysts and Intermediates in Alkyl-Aryl Kumada Coupling Reactions
}

\author{
Gerald Bauer, ${ }^{1}$ Matthew D. Wodrich, ${ }^{2}$ Rosario Scopelliti, ${ }^{1}$ and Xile $\mathrm{Hu}^{1 *}$ \\ ${ }^{1}$ Laboratory of Inorganic Synthesis and Catalysis, ${ }^{2}$ Laboratory for Computational Molecular Design, Institute of Chemical \\ Sciences and Engineering, École Polytechnique Fédérale de Lausanne (EPFL), EPFL-ISIC-LSCI, BCH 3305, Lausanne, CH \\ 1015, Switzerland. \\ E-mail: xile.hu@epfl.ch
}

\section{TOC Graph}

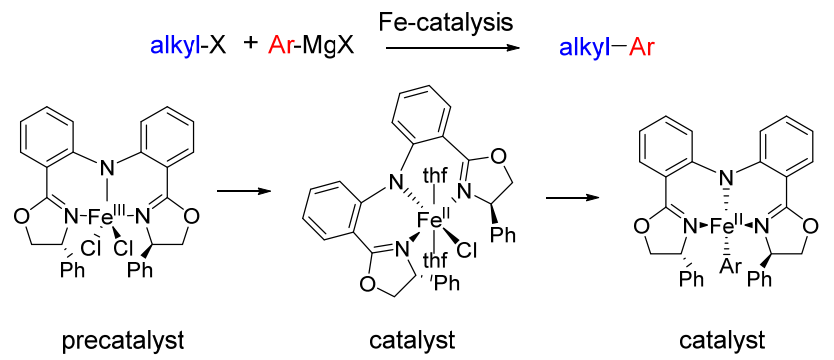


Abstract. Iron-catalyzed alkyl-aryl Kumada coupling has developed into an efficient synthetic method, yet its mechanism remains vague. Here, we apply a bisoxazolinylphenylamido pincer ligand (Bopa) to stabilize the catalytically active Fe center, resulting in isolation and characterization of well-defined iron complexes whose catalytic roles are probed and confirmed. Reactivity studies of the iron complexes identifies an Fe(II) "ate" complex, $\left[\mathrm{Fe}(\mathrm{Bopa}-\mathrm{Ph})(\mathrm{Ph})_{2}\right]^{\prime}$, as the active species for the oxidative addition of alkyl halide. Experiments using radicalprobe substrates and DFT computations reveal a bimetallic and radical mechanism for the oxidative addition. The kinetics of the coupling of an alkyl iodide with $\mathrm{PhMgCl}$ indicates that formation of the "ate" complex, rather than oxidative addition, is the turnover determining step. This work provides insights in iron-catalyzed cross coupling reactions of alkyl halides. 


\section{Introduction}

Iron-catalyzed cross coupling of alkyl halides with aryl Grignard reagents is amongst the most attractive methods for alkyl-aryl coupling for a number of reasons: (1) Iron is inexpensive, abundant, and non-toxic. (2) The ironcatalyzed alkyl-aryl Kumada coupling generally has a high yield, a short reaction time (within several hours) and a high functional group tolerance. (3) The use of alkyl electrophiles as the alkylating reagent allows the coupling of functionalized alkyl groups. ${ }^{1-5}$ Whereas significant progress has been made in developing new catalysts, reaction conditions, and scope, ${ }^{6-14}$ the mechanism of this and related iron-catalyzed coupling reactions of alkyl halides is only now being unveiled. Fürstner and co-workers showed that Fe-"ate" complexes, in which the formal oxidation states of $\mathrm{Fe}$ range from -2 to +2 , might be catalytically active, ${ }^{8,15}$ treatment of $\mathrm{FeCl}_{3}$ with a large excess of aryl Grignard reagents could lead to $\mathrm{Fe}(0)$-“ate" species. ${ }^{8}$ Further, they showed that a formal $\mathrm{Fe}(-2)$ complex, $\left[(\mathrm{Li}(\mathrm{TMEDA}))_{2} \mathrm{Fe}\left(\mathrm{C}_{2} \mathrm{H}_{4}\right)_{4}\right]$ was a highly active and selective catalyst for alkyl-aryl Kumada coupling. ${ }^{6}$ The lowvalent iron-"ate" species would be difficult to generate in most in-situ catalyst systems where reduction of the initial $\mathrm{Fe}(\mathrm{III})$ salt to $\mathrm{Fe}(0)$ or below by a Grignard reagent without $\beta$-hydrogen is difficult. In these cases, $\mathrm{Fe}(\mathrm{I})$ and $\mathrm{Fe}(\mathrm{II})$ "ate" complexes are more likely present. Neidig and co-workers reported that reaction of $\mathrm{FeCl}_{3}$ with $\mathrm{MeMgBr}$ in THF gave a homolytic tetramethyliron(III) complex $\left[\mathrm{MgCl}(\mathrm{THF})_{5}\right]\left[\mathrm{FeMe}_{4}\right]$ which then decomposed to give a $\mathrm{Fe}(\mathrm{I})$ species. ${ }^{16}$

Nagashima and co-workers observed the formation of (TMEDA)Fe(Mesityl) ${ }_{2}$ and (TMEDA)Fe(Mesityl)Br (TMEDA = tetramethylethylenediamine) from the coupling between 1-bromooctane and mesitylMgBr under conditions similar to the $\mathrm{FeCl}_{3}$-TMEDA protocol originally developed by Nakamura and co-workers. ${ }^{7}$ They proposed a catalytic cycle where a TMEDA-chelated Fe(II) was the active species. ${ }^{17}$ However, Bedford and co-workers showed that the reaction's active species was the homoleptic "ate" complex [Fe(mesityl) $\left.)_{3}\right]^{2}$. TMEDA seemed to trap intermediates in the off-cycle of the catalysis and suppressed side reactions. ${ }^{18}$ Bedford and co-workers also isolated defined $\mathrm{Fe}(\mathrm{I})$ phosphine complexes that were competent pre-catalysts in related Fe-catalyzed alkyl-aryl Negishi coupling, ${ }^{19,20}$ while Cárdenas and co-workers obtained EPR-based evidence for the involvement of Fe(I) carbene species in alkyl-alkyl Kumada coupling. ${ }^{21}$

A challenge in the mechanistic study of iron-catalyzed alkyl-aryl Kumada coupling is the coordinative lability of ligands on $\mathrm{Fe}$, especially when the latter undergoes oxidation and spin state changes. It is reported that TMEDA dissociates from the $\mathrm{Fe}(\mathrm{II})$ center during alkyl-aryl Kumada coupling, ${ }^{18}$ and even a bidentate phosphine ligand can leave an Fe ion during alkyl-aryl Negishi coupling. ${ }^{20}$ Therefore, extrapolation of active iron species from complexes isolated from the catalysis mixture or defined pre-catalysts might be error-prone without considering ligand dissociation. A strong chelating ligand can alleviate this complication. Herein we employ a bisoxazolinylphenylamido pincer ligand to support the catalytically active Fe center. The rigid tridentate chelate allows for the isolation and characterization of several intermediate species whose catalytic roles are probed. Subsequent experiments using radical-probe substrates, kinetic measurements, and DFT computations establish a catalytic cycle in which an Fe(II)-aryl-"ate" complex activates alkyl halide via a bimetallic oxidative addition pathway.

\section{Results}

\subsection{Synthesis, characterization, and reactivity of catalysts and intermediates}

The $\mathrm{Fe}(\mathrm{III})$ complex [Fe(Bopa-Ph)Cl $\mathrm{Cl}_{2}$ (1, Figure 1) was previously applied to iron-catalyzed hydrosilylation reactions. ${ }^{22,23}$ We believed that the pincer Bopa ligand might also be suitable for use in iron-catalyzed cross coupling reactions. The bis(aryl)amido pincer backbone provides both structural rigidity and chemical stability; the 
two oxazolinyl donors can accommodate both Fe(III) and Fe(II), and perhaps, for a short time, Fe(I) due to possible $\pi$-backbonding.

Complex 1 was first tested for the coupling of alkyl halides with $\mathrm{PhMgCl}$ (Figure 1). Fortunately, the coupling proceeded smoothly at both $-40^{\circ} \mathrm{C}$ and room temperature without needing an amine additive. Both primary and secondary alkyl halides could be coupled in high isolated yields, while either alkyl bromide or iodide may serve as suitable electrophiles. Thus, complex $\mathbf{1}$ is a competent pre-catalyst for iron-catalyzed alkyl-aryl Kumada coupling. Like many other catalysts, the coupling of alkyl chlorides and tertiary alkyl halides was inefficient.
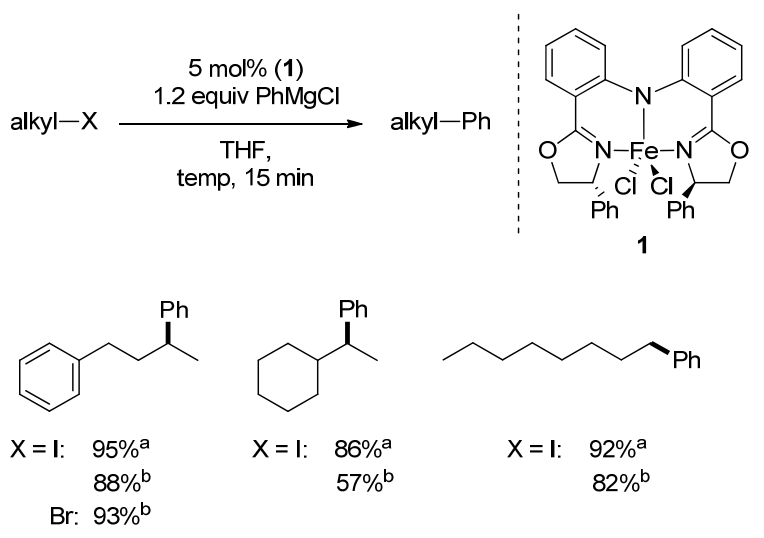

Figure 1. Alkyl-aryl coupling reactions catalyzed by complex 1. Isolated yields are reported. Note: (a) Reaction at $-40^{\circ} \mathrm{C}$; (b) Reaction at room temperature.

Complex 1 served as the entry point of our mechanistic study. The transformation of $\mathbf{1}$ by an aryl Grignard reagent was then examined. Addition of one equivalent of $\mathrm{PhMgCl}$ to a THF solution of $\mathbf{1}$ at room temperature produced [ $\left.\mathrm{Fe}(\mathrm{Bopa}-\mathrm{Ph}) \mathrm{Cl}(\mathrm{THF})_{2}\right]$ (2) (Scheme 1). The complex could, alternatively, be independently synthesized first by lithiating the pincer ligand followed by a metathesis reaction with $\mathrm{FeCl}_{2}(\mathrm{THF})_{1.5}$. The crystal structure of 2 (Figure 2) reveals an octahedrally coordinated Fe(II) center, with the pincer Bopa ligand adapting the expected meridional configuration. The complex has a solution magnetic moment of $5.11 \mu_{\mathrm{b}}{ }^{24}$ consistent with an $\mathrm{Fe}$ (II) complex in a high-spin state.

\section{Scheme 1. Synthesis of complexes 2, 4, and 5.}

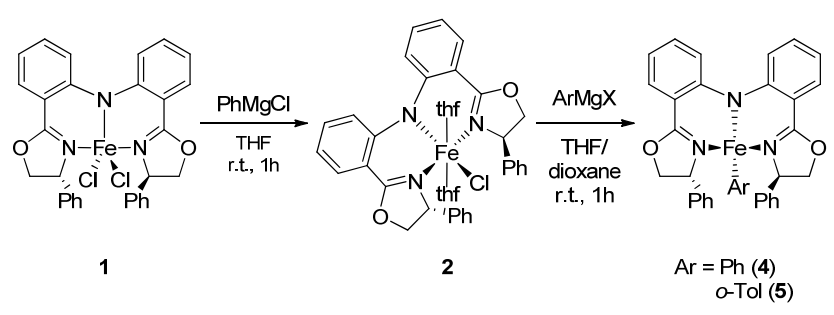




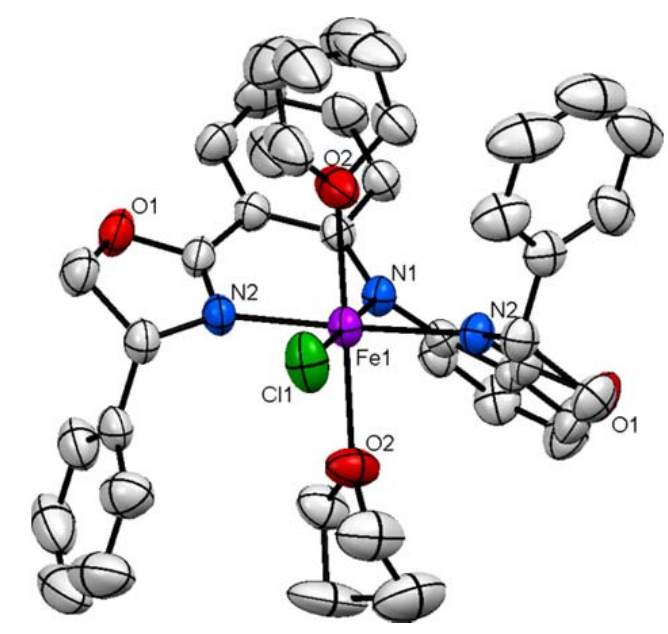

Figure 2. The molecular structure of complex 2. Hydrogen atoms are omitted for clarity. The thermal ellipsoids are displayed at a $50 \%$ probability. Selected bond lengths $(\AA)$ and angles (deg): $\mathrm{Fe}(1)-\mathrm{N}(1): 2.114(2) ; \mathrm{Fe}(1)-\mathrm{N}(2): 2.1256(16) ; \mathrm{Fe}(1)-\mathrm{O}(2): 2.2906(15) ; \mathrm{Fe}(1)-$ $\mathrm{Cl}(1): 2.4152(9) ; \mathrm{N}(1)-\mathrm{Fe}(1)-\mathrm{N}(2): 85.41(5) ; \mathrm{N}(2)-\mathrm{Fe}(1)-\mathrm{N}(2): 170.81(9) ; \mathrm{N}(1)-\mathrm{Fe}(1)-\mathrm{O}(2)$ : 91.03(5); N(2)-Fe(1)-O(2): 86.32(7); N(1)$\mathrm{Fe}(1)-\mathrm{Cl}(1): 180.00(6): \mathrm{N}(2)-\mathrm{Fe}(1)-\mathrm{Cl}(1): 94.59(5))$

Concomitant to the reduction of $\mathbf{1}$ to 2, 0.5 equivalents of biphenyl were formed, indicating that the phenyl anion in $\mathrm{PhMgCl}$ was the electron donor in this process. Complex 2 is unreactive towards (3-iodobutyl)benzene (3), suggesting that 2 requires further transformation during the catalytic process. Indeed, further addition of $\mathrm{PhMgCl}$ to a solution of $\mathbf{2}$ shows an immediate reaction that does not produce additional biphenyl, suggesting that the $\mathrm{Fe}-$ center is not further reduced. The reactions of $\mathbf{2} \mathrm{ArMgCl}(\mathrm{Ar}=\mathrm{Ph}, o-\mathrm{Tol})$ gave $[\mathrm{Fe}(\mathrm{Bopa}-\mathrm{Ph})-\mathrm{Ar}](\mathbf{4}, \mathbf{A r}=\mathbf{P h} ; \mathbf{5}$, Ar $=\mathbf{o}$-Tol). The crystal of 5 was obtained in a THF-dioxane mixture and its structure revealed the 4-coordinate nature of the complex in the solid state (Figure 3), where the Fe ion adopts a tetrahedral geometry. While a crystal structure of $\mathbf{4}$ could not be obtained, its composition was confirmed by elemental analysis. Complexes $\mathbf{4}$ and $\mathbf{5}$ have solution magnetic moments of 5.00 and $4.76 \mu_{\mathrm{b}}$, respectively, ${ }^{24}$ consistent with each complex having a highspin Fe(II) center. In the presence of one equivalent $\mathrm{PhMgCl}, 4$ decomposed with a half-life of about 10 min at room temperature. The color of the solution changed from deep red to a turbid brown and NMR spectrum of the solution suggested the formation of a Mg-Bopa-Ph adduct. No biphenyl was observed. This evidence indicates that in the absence of alkyl halide, 4 may be decomposed by an excess amount of $\mathrm{PhMgCl}$ via iron demetallation. ${ }^{24}$ However, this decomposition is too slow to be catalytically relevant, except at the end of the catalysis where the iron complex has been demetallated to form a presumable Mg-Bopa species. 


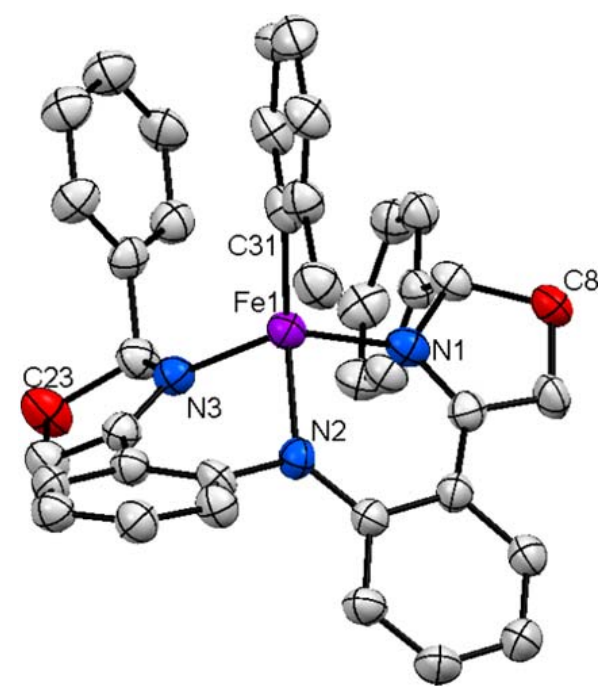

Figure 3. The molecular structure of complex 5. Hydrogen atoms and a co-crystallized 1,4-dioxane molecule are omitted for clarity. The thermal ellipsoids are displayed at a 50\% probability. Selected bond lengths $(\AA)$ and angles (deg): $\mathrm{Fe}(1)-\mathrm{N}(2): 2.032(4) ; \mathrm{Fe}(1)-\mathrm{N}(1)$ : 2.033(4); $\mathrm{Fe}(1)-\mathrm{C}(31): 2.053(5) ; \mathrm{Fe}(1)-\mathrm{N}(3): 2.083(4) ; \mathrm{N}(2)-\mathrm{Fe}(1)-\mathrm{N}(1): 90.25(15) ; \mathrm{N}(2)-\mathrm{Fe}(1)-\mathrm{C}(31): 127.37(18) ; \mathrm{N}(1)-\mathrm{Fe}(1)-\mathrm{C}(31)$ : 110.88(16); N(2)-Fe(1)-N(3): 87.65(15); N(1)-Fe(1)-N(3): 114.31(15); C(31)-Fe(1)-N(3): 121.52(18).

To analyze the reactivity and the catalytic relevance of complex 4, this complex was reacted with 20 equivalents of (3-iodobutyl)benzene (3) at $-40^{\circ} \mathrm{C}$ in a THF solution to give the $\mathrm{C}-\mathrm{C}$ coupled product 1,3 -diphenylbutane (7) (Table 1). However, the reaction was slow in comparison to the catalysis, as $50 \%$ conversion $\left(\mathrm{t}_{1 / 2}\right)$ required forty minutes (Entry 1, Table 1), whereas the catalysis was generally completed within several minutes. The difference in reaction rates suggests that $\mathbf{4}$ is not the active species to activate alkyl halides in the catalytic reaction. In the presence of $\mathrm{PhMgCl}$ and $\mathrm{PhLi}$, the reaction of 4 with 3 was greatly accelerated. The $\mathrm{t}_{1 / 2}$ was less than $15 \mathrm{sec}$ (Entries 2 and 3, Table 1) which was comparable to the rate of the catalytic coupling reaction. This result suggests that 4 reacted with $\mathrm{PhMgCl}$ to form either an associated species, [ $\mathrm{Fe}(\mathrm{Bopa}-\mathrm{Ph}) \mathrm{Ph}](\mathrm{PhMgCl})$, or an "ate"complex, $\left[\mathrm{Fe}(\mathrm{Bopa}-\mathrm{Ph}) \mathrm{Ph}_{2}\right]^{-}$, as the catalytic active species.

Table 1. Influence of Additive on the Reaction of Complex 4 with 3.

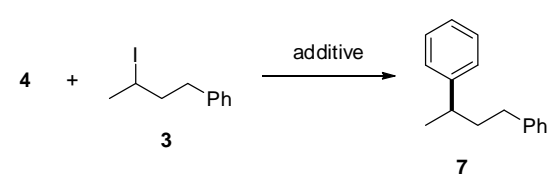

\begin{tabular}{lll}
\hline Entry & Additive & $\mathrm{t}_{1 / 2}$ \\
\hline 1 & none & $40 \mathrm{~min}$ \\
2 & $\mathrm{PhMgCl}$ & $<15 \mathrm{sec}$ \\
3 & $\mathrm{PhLi}$ & $<15 \mathrm{sec}$ \\
\hline
\end{tabular}

To probe whether an associated species or an "ate"-complex is involved, two cross-over experiments were performed. First, the reaction of $\mathbf{4}$ with $\mathbf{3}$ in the presence of o- $\mathrm{TolMgCl}$ was examined in THF at room temperature (Table 2). Both 1,3-diphenylbutane (7) and 3-(2-methylphenyl)-1-phenylbutane (8) were produced. When the 
ratio of 4 to $o-\mathrm{TolMgCl}$ was increased, the ratio of 7 to 8 increased in a similar manner (Table 2). Second, the reactions of complex 5 with 3 in the presence of $\mathrm{PhMgCl}$ were conducted, ${ }^{24}$ yielding coupling products containing both $\mathrm{Ph}$ and o-Tol groups. These results are more consistent with the active species being the "ate" complex, $\left[\mathrm{Fe}(\mathrm{Bopa}-\mathrm{Ph}) \mathrm{Ar}_{2}\right]^{-}(6)$, where the two aryl groups behave similarly in catalysis.

Table 2. Influence of o-TolMgCl on the Reaction of Complex 4 with 3.

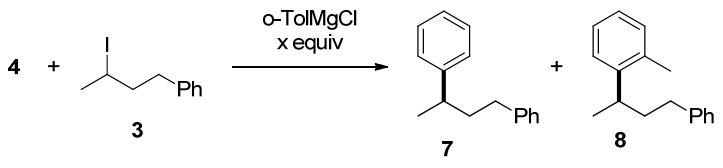

\begin{tabular}{llllrl}
\hline Entry & $\begin{array}{l}\text { Equiv. } \\
\text { oTolMgCl }\end{array}$ & $\begin{array}{l}\text { Ratio } \\
\mathbf{4} / \text { oTolMgCl }\end{array}$ & $\begin{array}{l}\text { Yield } / \mathbf{8} \text { (conversion of 3) } \\
\text { (\%) }\end{array}$ & $\begin{array}{l}\text { Ratio } \\
\mathbf{7 / 8}\end{array}$ \\
\hline 1 & 1.0 & 1.0 & $37 / 45(92)$ & 0.8 \\
2 & 0.8 & 1.3 & $32 / 33(73)$ & 1.0 \\
3 & 0.6 & 1.7 & $33 / 30(71)$ & 1.1 \\
4 & 0.4 & 2.5 & $33 / 19(60)$ & 1.7 \\
\hline
\end{tabular}

\subsection{Mechanism of cross coupling}

After the transmetalation step ( 2 to 4 ) and the activation step (4 to 6) were examined, the oxidative addition of alkyl halide was probed. The results of radical clock experiments indicate that the oxidative addition produces alkyl radicals (Scheme 2). For example, the coupling of enantiomerically enriched 3-bromo-1-phenylbutane (9) led to the racemic product (10) while coupling of (bromomethyl)cyclopropane (11) gave almost exclusively the ring-opened product (12-L).

Scheme 2. Evidence for a radical pathway in the activation of alkyl halide.

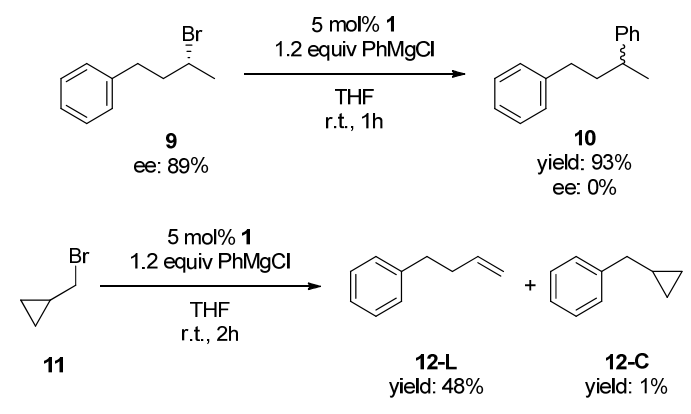

We propose that the first step of oxidative addition is a single electron transfer between an iron(II) bis(aryl)-ate species, represented here by 6, and an alkyl halide to give an Fe(III) halide complex (13) and an alkyl radical (Scheme 3). The alkyl radical then may engage in one of the three possible pathways to give the coupling product: cage-rebound, escape-rebound, or bimetallic oxidative addition. ${ }^{25}$ In the cage-rebound pathway (Pathway A, Scheme 3), the alkyl radical stays in the solvent cage and recombines with $\mathbf{1 3}$ to give a $[\mathrm{Fe}(\mathrm{IV})(\mathrm{Ph})(\mathrm{Alkyl})(\mathrm{X})]$ $(\mathbf{1 4}, \mathrm{X}=$ halide) which, upon reductive elimination, gives the coupling product and regenerates complex 2 , or its 
analogue (2-X). In the escape-rebound pathway (Pathway B, Scheme 3), the alkyl radical first leaves the solvent cage and then re-enters it to combine with 13 to give complex 14. Reductive elimination from $\mathbf{1 4}$ then yields the coupling product. In the bimetallic oxidative addition pathway (Pathway C, Scheme 3), the alkyl radical leaves the solvent cage and combines with another molecule of Fe(II) phenyl complex 4 to form a [Fe(III)(Ph)(Alkyl)] complex (15). Reductive elimination from 15 gives the coupling product and an $\mathrm{Fe}(\mathrm{I})$ complex (16) which reacts with an Fe(III) complex 13 to give Fe(II) complexes 2 and 4 . In our considerations we neglect the possibility that C-C coupling occurs via attack of free radical on an Fe-aryl species; Norbby and co-workers reported a competitive Hammett study that ruled out radicals in the coupling step. ${ }^{26}$

Scheme 3. Three possible pathways for the oxidative addition of alkyl halide and the consequent reductive elimination.

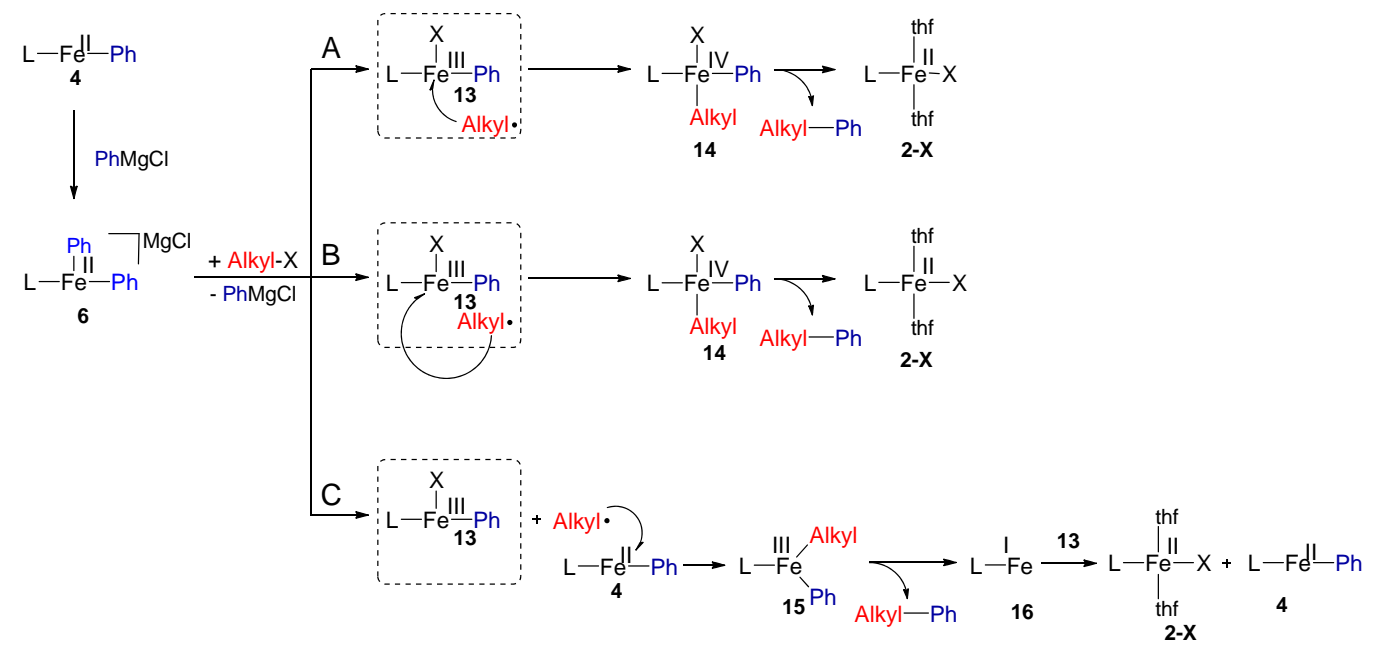

Scheme 4. Coupling of a radical-clock substrate to differentiate the pathways for oxidative addition and C-C bond formation.

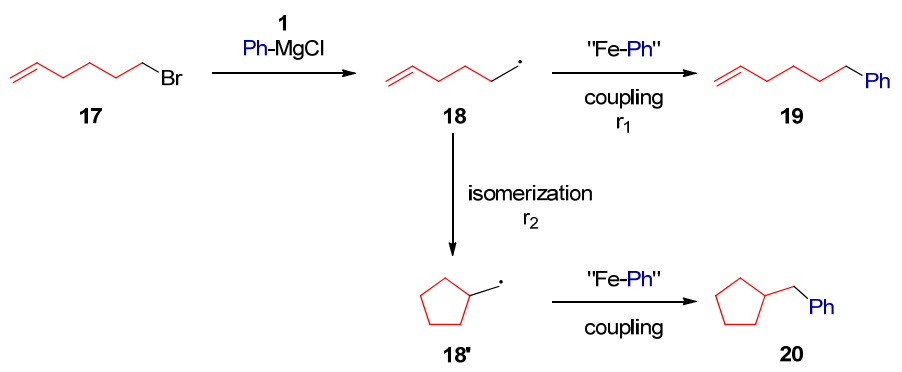

The reaction outcomes of the coupling of radical-probe substrates can be used to distinguish the cage-rebound pathway from the escape-rebound and bimetallic oxidative addition pathway. ${ }^{25,27-30}$ In the current case, the coupling of 1-bromo-5-hexene (17) with $\mathrm{PhMgCl}$ in the presence of 1 was employed for this purpose (Scheme 4). Activation of 17 first gives the alkyl radical (18) that can combine with an Fe-Ph species to give the linear coupling product 19. Radical 18 can also undergo an intramolecular ring-closing rearrangement $\left(\mathrm{k}_{2} \approx 10^{5} \mathrm{~s}^{-1}\right)$ to give a cyclized radical 18, ${ }^{31}$ Combination of 18' with an Fe-Ph intermediate then gives the cyclized coupling product 20. The ratio of $\mathbf{1 9}$ and $\mathbf{2 0}$ is a function of $r_{1}$ and $r_{2}$. For all scenarios $r_{2}=k_{2}[\mathbf{1 8}]$. However, $r_{1}$ depends upon the 
reaction pathway. In the cage-rebound pathway, the recombination is considered an intramolecular reaction and is $0^{\text {th }}$ order on the iron catalyst. Hence, $r_{1}=k_{1}[\mathbf{1 8}]$, and $r_{1} / r_{2}$ is independent of the concentration of the iron catalyst. It follows that the ratio of $\mathbf{1 9} / \mathbf{2 0}$ is independent of catalyst loading. On the other hand, in the bimetallic oxidative addition and escape-rebound pathways, the combination of an alkyl radical with an iron ion is an intermolecular reaction and is $1^{\text {st }}$ order on the catalyst. Therefore, $\mathrm{r}_{1}=\mathrm{k}_{1}$ [cat][18], and the ratio of $\mathbf{1 9} / \mathbf{2 0}$ is $1^{\text {st }}$ order on catalyst loading.

Figure 4 shows that the ratio of $\mathbf{1 9 / 2 0}$ is linearly dependent on the loading of catalyst (1) in the coupling of $\mathbf{1 7}$ with $\mathrm{PhMgCl}$. This result eliminates the cage-rebound pathway; however, it is consistent with either an escaperebound or a bimetallic oxidative addition mechanism.

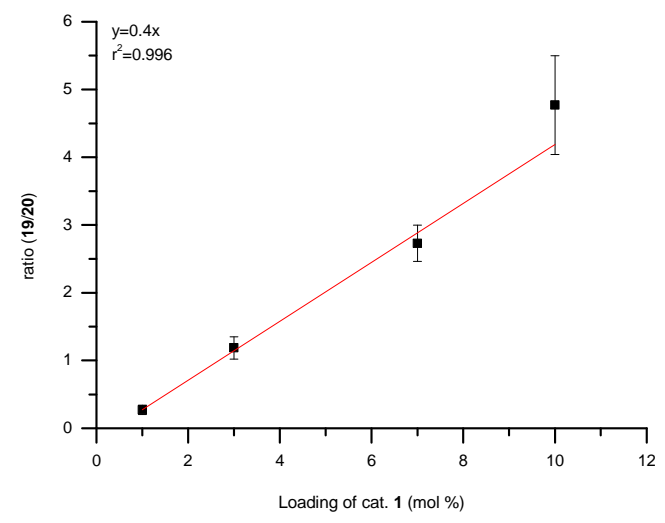

Figure 4. Ratio of $\mathbf{1 9} / \mathbf{2 0}$ in the coupling of $\mathbf{1 7}$ with $\mathrm{PhMgCl}$ as a function of catalyst loading. The results are averaged over 2 independent runs.

To probe the feasibility of the bimetallic oxidative addition, the reaction of $\mathbf{4}$ with an in-situ formed alkyl radical was examined (Scheme 5). If this mechanism is operating, the combination of $\mathbf{4}$ with an alkyl radical will lead to an alkyl-aryl coupling product, as predicted by Path $\mathrm{C}$ in Scheme 3. In the experiment a phenylpropyl radical was generated by the photolysis of tert-butyl 4-phenylbutaneperoxoate (21) ${ }^{32}$ In the presence of one equivalent of 4, 1,3-diphenylpropane was formed in a $27 \%$ yield (relative to 4 ). The formation of the alkyl-aryl coupled product in this process, in turn, indicates that the bimetallic oxidative addition pathway proposed in Scheme 3 is probable, although it is not a proof. As the Fe(III) halide complex 13 cannot be isolated, an analogous reactivity test cannot be conducted to probe the feasibility of the escape-rebound mechanism.

Scheme 5. Reaction of 4 with an in-situ generated alkyl radical.<smiles>CC(C)(C)OOC(=O)CCCc1ccccc1</smiles> 
To elucidate additional mechanistic details we employed density functional theory computations at the

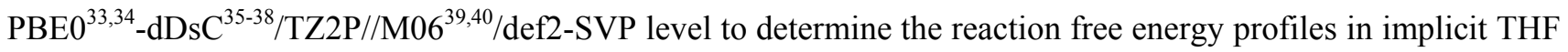
solvent (using the COSMO-RS ${ }^{41}$ solvation model) of the bimetallic oxidative addition and escape-rebound pathways (see supporting information for computational details). ${ }^{24}$ Owing to the extremely flat nature of the full catalyst potential energy surface (PES), our computations employed a model of the Fe catalyst in which some methyl groups replaced some phenyl groups. In the model, the aryl nucleophile is represented using a tosyl moiety while the isopropyl radical represents the alkyl group.

Figure 5 illustrates the bimetallic oxidative addition pathway. Beginning from the reactant complex $\left(4+\mathbf{P P r}^{*}\right)$, the isopropyl radical first associates with the $\mathrm{Fe}(\mathrm{II})$ center by overcoming a small transition state barrier, $\mathbf{T S}_{4,15}(+6.3$ $\mathrm{kcal} / \mathrm{mol}$ ), thereby forming a $\mathrm{Fe}$ (III) species characterized by a high-spin sextet, $\mathbf{1 5}_{\text {sextet }}$, in which both the aryl and alkyl groups are bound to the iron center. Initial computations on the sextet PES revealed the reductive elimination step leading to final product formation to be energetically inaccessible (e.g., $>60 \mathrm{kcal} / \mathrm{mol}$ at the M06/def2-SVP level). As a result, we examined the possibility that the final product forming steps occur on the PES of the intermediate spin quartet state rather than sextet PES, as the energies of $\mathbf{1 5}_{\text {Sextet }}$ and $\mathbf{1} \mathbf{5}_{\text {Quartet }}$ lie within $4 \mathrm{kcal} / \mathrm{mol}(+6.6 \mathrm{kcal} / \mathrm{mol}$ at the M06/def2-SVP level). Indeed, a minimum energy crossing point (MECP) between the high (sextet) and intermediate (quartet) spin states was located $\sim 11 \mathrm{kcal} / \mathrm{mol}$ above $\mathbf{1 5}_{\text {Sextet }}$ and $\sim 4$ $\mathrm{kcal} / \mathrm{mol}$ above $\mathbf{1 5}_{\text {Quartet }}$ (Figure 6). Proceeding along the reaction coordinate, $\mathbf{1 5}_{\text {Quartet }}$ adopts a more stable conformer, $\mathbf{1 5}^{\prime}$ Quartet, in which the carbon atoms of the aryl and alkyl groups that ultimately form the new C-C bond are in closer proximity $\left(3.060 \AA\right.$ for $\mathbf{1 5}_{\text {Quartet }}$ vs $2.707 \AA$ for $\mathbf{1 5}_{\text {Quartet }}$ ). From $\mathbf{1 5}_{\text {Quartet }}$ reductive elimination forms the final product (16). The highest point on the bimetallic oxidative addition PES corresponds to the reductive elimination TS located $10.8 \mathrm{kcal} / \mathrm{mol}$ above the reactant complex. 


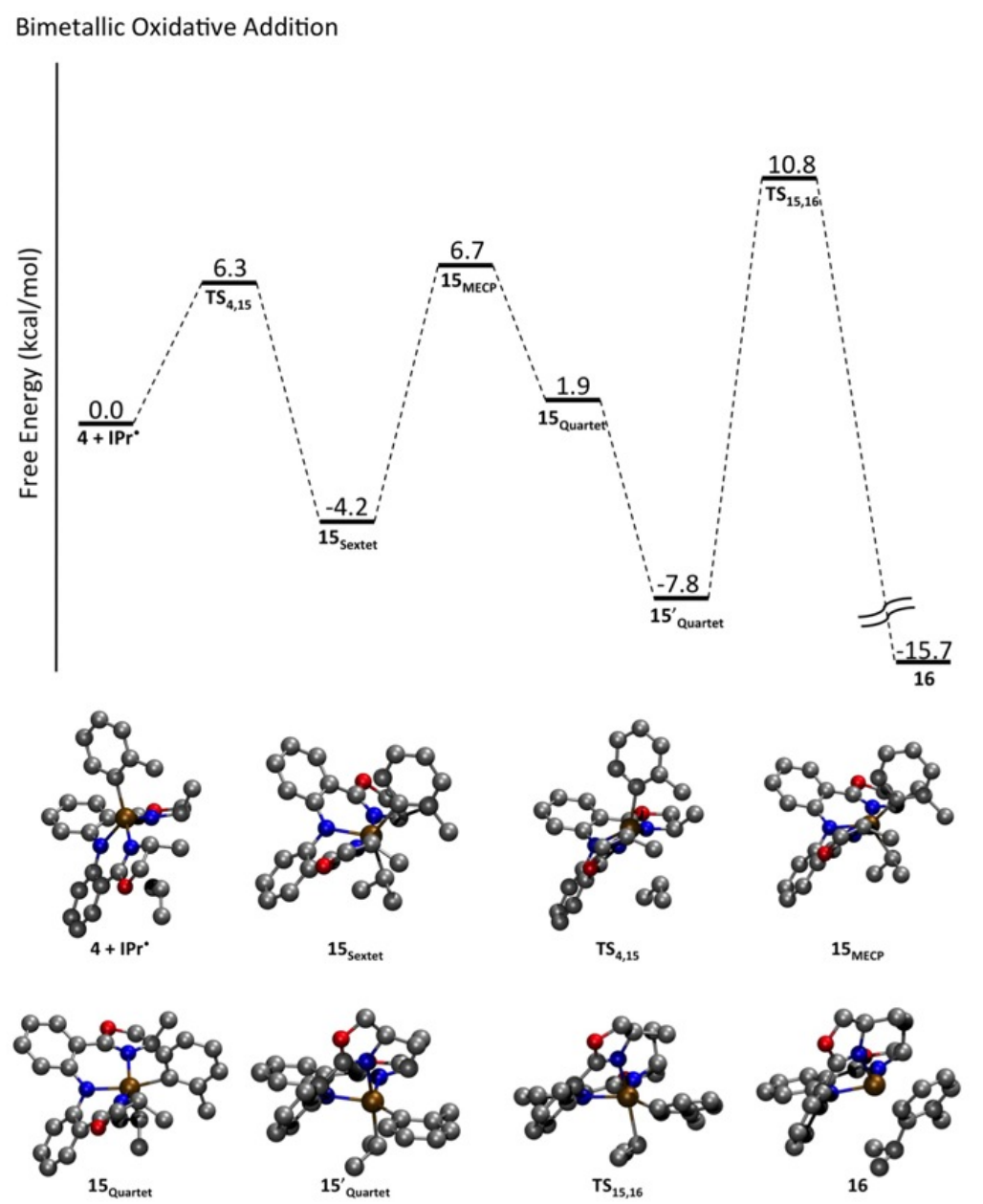

Figure 5. Reaction free energy profile and relevant structures for the bimetallic oxidative addition pathway computed at the unrestricted PBE0-dDsC/TZ2P//M06/def2-SVP level (including THF implicit solvation using the COSMO-RS model).

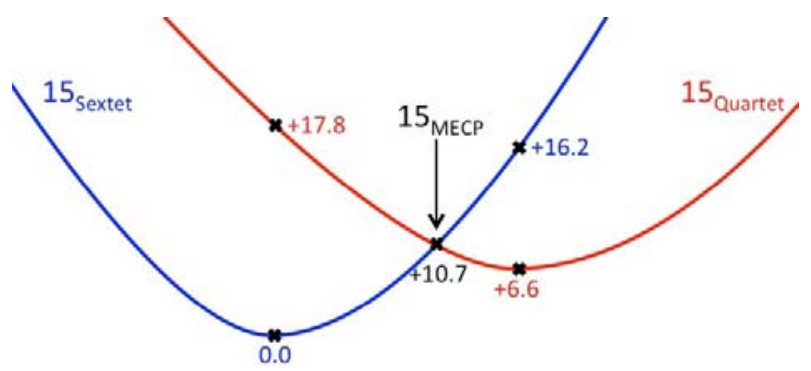

Figure 6. Relative electronic energies (at the M06/def2-SVP level) of the sextet (blue), quartet (red), and minimum energy crossing point (MECP, black) of 15. Values in $\mathrm{kcal} / \mathrm{mol}$.

The escape-rebound pathway represents a second possible mechanism for forming the coupled product. Moving from the high-spin quintet $\mathrm{Fe}(\mathrm{III})$ reactant complex $(\mathbf{1 3}+\mathrm{iPr})$ to the TS corresponding to association of the alkyl radical requires $10.6 \mathrm{kcal} / \mathrm{mol}$ of energy (Figure 7). The Fe(IV) intermediate 14 in which both the alkyl, aryl, and halogen groups are bound is roughly isoenergetic with $\mathbf{T S}_{\mathbf{1 3 , 1 4}}\left(\mathbf{T S}_{\mathbf{1 3 , 1 4}} \rightarrow \mathbf{1 4}-0.65 \mathrm{kcal} / \mathrm{mol}\right.$ at the M06/def2-SVP level). Product formation via reductive elimination requires an addition $3.4 \mathrm{kcal} / \mathrm{mol}$ of energy to overcome the TS barrier $\left(\mathbf{1 4} \rightarrow \mathbf{T S}_{14,2 \mathrm{X}}\right)$. Given that the highest point on this pathway lies higher in energy than proceeding 
through the bimetallic oxidative addition route ( $14.3 \mathrm{vs} .10 .8 \mathrm{kcal} / \mathrm{mol})$, the DFT computations indicate that bimetallic oxidative addition is the favored mechanistic pathway. Although the energy difference is small given the uncertainty of DFT calculations, because the concentration of Fe(II) species 4 is much higher than Fe(III) species 13 during catalysis, the bimetallic oxidative addition should be the dominant reaction pathway.

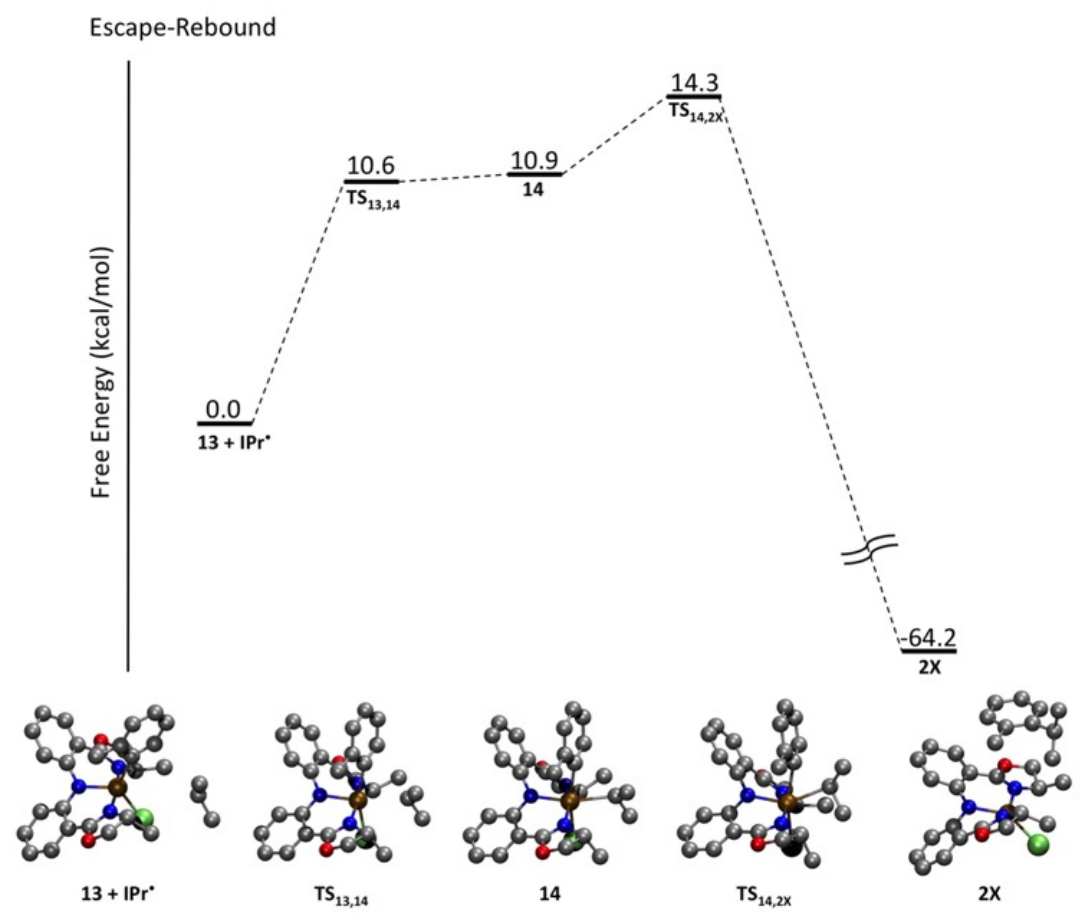

Figure 7. Reaction free energy profile and relevant structures for the escape-rebound pathway computed at the unrestricted PBE0$\mathrm{dDsC} / \mathrm{TZ2P} / / \mathrm{M} 06 / \mathrm{def} 2-\mathrm{SVP}$ level (including THF implicit solvation using the COSMO-RS model).

\subsection{Kinetics}

The kinetics of the Fe-catalyzed alkyl-aryl coupling was determined using complex $\mathbf{2}$ as the catalyst. Complex $\mathbf{1}$ was not suitable for the kinetic studies since the reduction from $\mathbf{1}$ to 2 is slow at $-84^{\circ} \mathrm{C}$ and leads to an induction period. The use of complex $\mathbf{2}$ is justified because $\mathbf{1}$ and $\mathbf{2}$ have the same efficiency for the reactions shown in Figure 1. The coupling reaction rates between (3-iodobutyl)benzene (3) and $\mathrm{PhMgCl}$ ( $5 \mathrm{~mol} \% 2$ as catalyst) were measured using the initial rate approximation. ${ }^{24}$ Figures $8(\mathrm{~A})$ and $8(\mathrm{~B})$ show the dependence of the reaction rate on the concentration of $\mathrm{PhMgCl}$ and catalyst, respectively. The data approximately fits with a $1^{\text {st }}$ order in Grignard reagent and $2^{\text {nd }}$ order in catalyst. Only a small and random change in the reaction rate was observed when the substrate (3) concentration was varied (Figure 8C). This result suggested that the reaction is $0^{\text {th }}$ order in alkyl iodide. To further confirm this, the reaction profile of a given catalytic run was evaluated by the integrated rate law (in the range of up to $77 \%$ conversion). The conversion of the substrate could be fit with a $1^{\text {st }}$ order decay. ${ }^{24}$ Assuming a constant concentration of catalyst, the result agrees with a $1^{\text {st }}$ order in Grignard and $0^{\text {th }}$ order in substrate. The coupling of 3 and $\mathrm{PhMgCl}$ was also monitored by UV-Vis spectroscopy. Although the spectral change might be consistent with the resting state of the catalyst being the Fe(II) phenyl complex $\mathbf{4}$, definitive assignment is difficult due to overlap of absorption bands. ${ }^{24}$ 

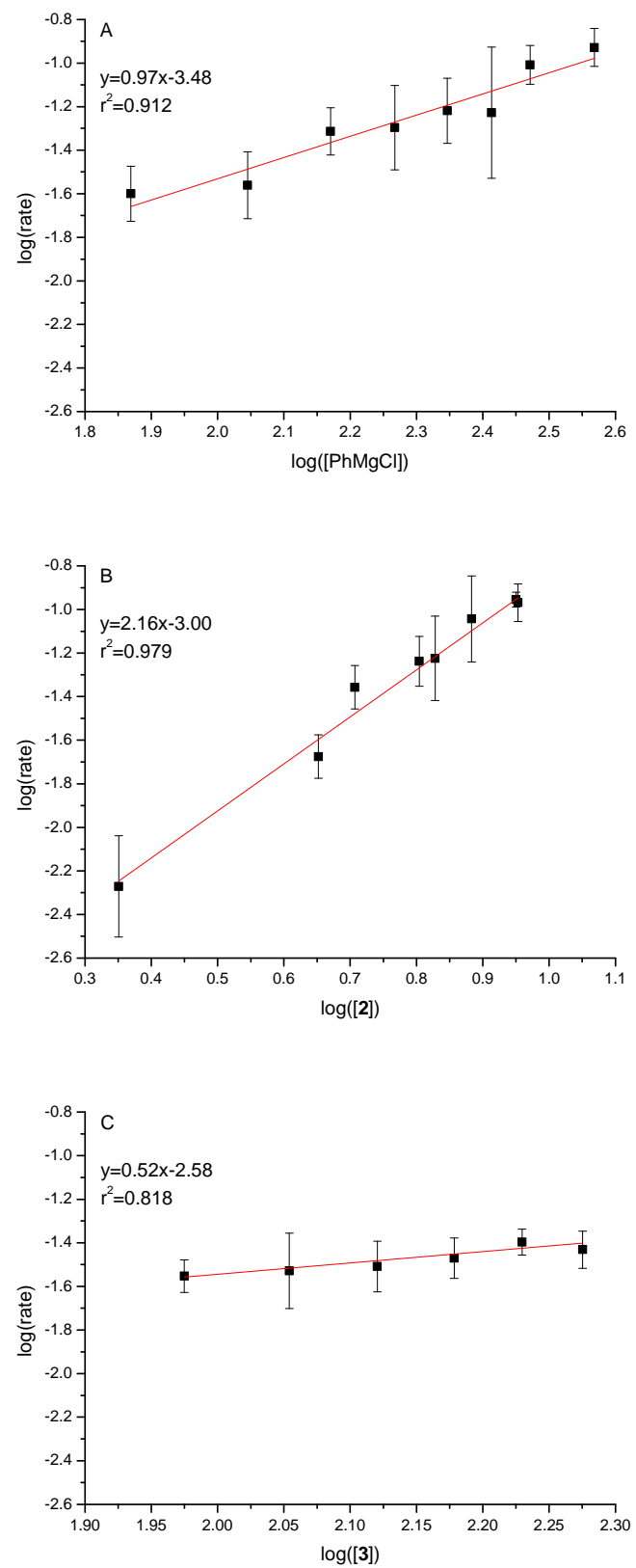

Figure 8. The influence of the concentrations of Grignard reagent (A), catalyst (B), and alkyl iodide (C) in the initial rates of the coupling of 3 with $\mathrm{PhMgCl}$. The slope of the log rate vs. log reagent rounded to an integral is the approximate rate order in (A) and (B). The data are averaged over minimum 3 independent runs.

\section{Discussion}

Based on the results described in the previous section, a catalytic cycle can be proposed (Scheme 6). The Fe(III) pre-catalyst, $\left[\mathrm{Fe}(\mathrm{Bopa}-\mathrm{Ph}) \mathrm{Cl}_{2}\right]$ (1), is first reduced by $\mathrm{PhMgCl}$ to form the $\mathrm{Fe}(\mathrm{II})$ catalyst, [Fe(Bopa$\mathrm{Ph}) \mathrm{Cl}(\mathrm{THF})_{2}$ ] (2). Transmetalation of complex 2 with $\mathrm{PhMgCl}$ gives [Fe(Bopa- $\left.\mathrm{Ph}\right) \mathrm{Ph}$ ] (4), which is proposed as the resting state of the catalyst. Species $\mathbf{4}$ is activated by another molecule of $\mathrm{PhMgCl}$ to give an "ate" complex $\left[\mathrm{Fe}(\mathrm{Bopa}-\mathrm{Ph})(\mathrm{Ph})_{2}\right]^{-}(\mathbf{6})$. Fürstner and co-workers showed that $\mathrm{FeCl}_{3}$ reacted with an excess of MeLi in ether to 
give an analogous $\mathrm{Fe}(\mathrm{II})$-ate complex $\left[\left(\mathrm{Me}_{4} \mathrm{Fe}\right)(\mathrm{MeLi})\right]\left(\mathrm{Li}^{*} \mathrm{Et}_{2} \mathrm{O}\right)_{2}$ which is capable of methylation of vinyl and acyl electrophiles. ${ }^{15}$ Neidig and co-workers showed that $\mathrm{FeCl}_{3}$ reacted with $\mathrm{MeMgBr}$ in THF to give a $\mathrm{Fe}$ (III)-ate complex $\left[\mathrm{MgCl}(\mathrm{THF})_{5}\right]\left[\mathrm{FeMe}_{4}\right]$ that reductively eliminated ethane, supporting the catalytic role of ate complexes. ${ }^{16}$ While the exact structure and composition remain unclear, the two Ph groups in complex 6 appear equivalent in reactivity. Species 6 reacts much faster than $\mathbf{4}$ with alkyl halide; therefore, it is the relevant active species for oxidative addition. Reaction of $\mathbf{6}$ with alkyl halide gives an alkyl radical and an $\mathrm{Fe}$ (III) complex, [Fe(Bopa$\mathrm{Ph})(\mathrm{Ph})(\mathrm{X})](13, \mathrm{X}=$ halide). The alkyl radical escapes the solvent cage and recombines with another molecule of a Fe(II) aryl complex, i.e. 4 (it could be 6 as well), to give [Fe(Bopa-Ph)(Ph)(Alkyl)] (15). Reductive elimination from 15 gives the alkyl-aryl coupled product and an $\mathrm{Fe}(\mathrm{I})$ species [Fe(Bopa-Ph)] (16). Species 16 should be unstable and quickly react with the unstable Fe(III) complex 13, to give the two Fe(II) complexes 2 and $\mathbf{4}$ which can re-enter the catalytic cycle.

Scheme 6. A proposed catalytic cycle for the coupling of alkyl halide with PhMgCl. The X ligand in species 2 and 13 is identical to the $\mathrm{X}$ group in alkyl-X. The pincer Bopa-Ph is simplified for clarity.

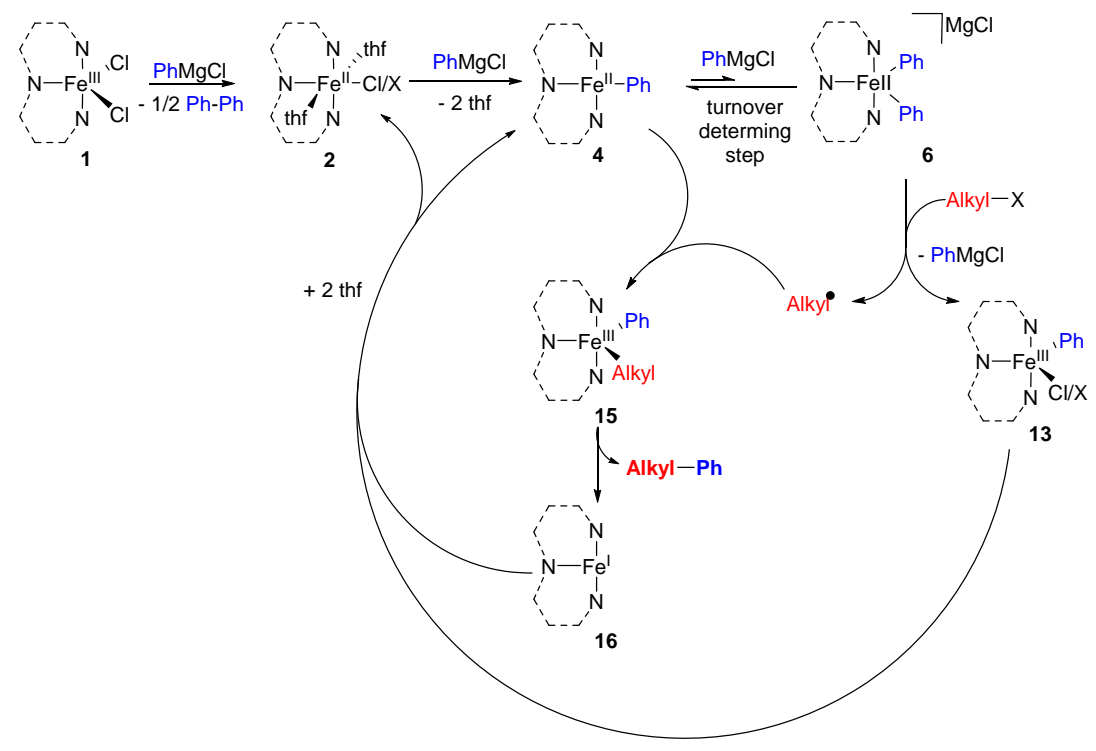

Several deviations from this catalytic cycle could be proposed. For example, the alkyl radical might combine with species 6 rather than 4 to an Fe(III) species analogous to 15. This variation does not significantly alter the overall catalytic cycle. On the other hand, species 16 might react with an alkyl halide to generate an alkyl radical and the $\mathrm{Fe}(\mathrm{II})$ species 2, which would result in a different catalytic cycle where the transformation of $\mathbf{4}$ to $\mathbf{6}$ serves only as the initiation step. However, this possibility is incompatible with $\mathbf{4}$ being the resting state and the catalysis being $1^{\text {st }}$ order in Grignard reagent. Furthermore, it is inconsistent with the reaction profile of the catalysis that shows no change of kinetic behavior over the reaction course.

The kinetics of the catalysis, i.e. $2^{\text {nd }}$ order in catalyst, $1^{\text {st }}$ order in Grignard, and $0^{\text {th }}$ order in alkyl iodide, indicates that transmetalation, but not oxidative addition, is the turnover determining step. The $2^{\text {nd }}$ order in catalyst suggests that the transformation of $\mathbf{4}$ to $\mathbf{6}$ goes through a bimetallic intermediate; a possibility is shown in Scheme 7. Dimeric Fe(II) $\mu$-aryl complexes such as $\left[\mathrm{Fe}_{2}(\text { mesityl) })_{4}\right]\left(\mathbf{1 7}\right.$, Scheme 8), ${ }^{42,43}\left[\mathrm{Fe}_{2}\left(2,4,6-{ }^{\mathrm{i}} \mathrm{Pr}_{3} \mathrm{C}_{6} \mathrm{H}_{2}\right)_{4}\right](\mathbf{1 8}),{ }^{43}$ and $\left[\{\mathrm{Ar} * \mathrm{Fe}(\mu-\mathrm{Ph})\}_{2}\left(\mathrm{Ar} *=\mathrm{C}_{6} \mathrm{H}_{3}-2,6-\left(\mathrm{C}_{6} \mathrm{H}_{2}-2,4,6-{ }^{\mathrm{i}} \mathrm{Pr}_{3}\right)_{2} \quad(\mathbf{1 9})^{44}\right.\right.$ have previously been reported. Furthermore, 
$\left[\mathrm{Fe}_{2}(\text { mesityl })_{4}\right]$ reacts with mesitylMgBr to form the tris(mesityl)ferrate (20), which could activate the alkyl halide. $^{18}$

Scheme 7. A hypothetical mechanism for the transformation of 4 to 6.

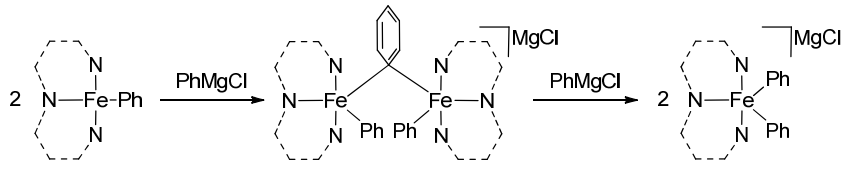

Scheme 8. Structure and reactivity of some $\mathrm{Fe}(\mathrm{II}) \mu$-aryl complexes.

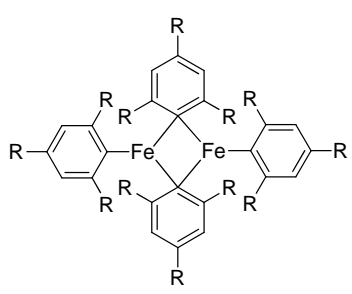

$17, \mathrm{R}=\mathrm{Me}$ 18, $R=i P r$

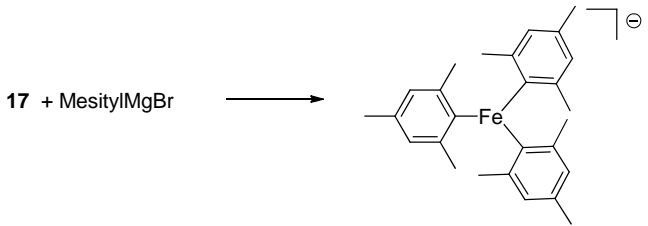

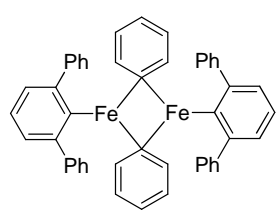

19

20

The mechanism described here might be compared with those recently proposed for Fe-catalyzed, TMEDAassisted alkyl-aryl Kumada coupling. ${ }^{18}$ When a bulky aryl Grignard reagent such as mesitylMgBr is used, homoleptic $\left[\mathrm{Fe}(\text { mesityl })_{3}\right]^{-}$is the catalyst and TMEDA does not serve as a ligand. If less bulky aryl Grignard reagents are used, then the true catalyst is unknown, although there is EPR evidence for an $\mathrm{Fe}(\mathrm{I})$ species in the reaction mixture. In the present system, ligated Fe(II) complexes are genuine catalysts for the coupling. This is due to the strong chelating ability of the tridentate pincer ligand Bopa which, in turn, facilitates the mechanistic study. As in the Fe-TMEDA system for the coupling of less bulky Grignard reagent, the Fe(I) species (16) is involved; but this $\mathrm{Fe}(\mathrm{I})$ species is an unstable intermediate rather than a resting species in the former. Stable Fe(I) species have been shown as catalysts in Fe-catalyzed alkyl-aryl Negishi coupling ${ }^{19,20}$ and alkyl-alkyl Kumada coupling. ${ }^{21}$ These $\mathrm{Fe}(\mathrm{I})$ species are supported by soft, neutral donors such as phosphine and N-heterocyclic carbene ligands which match well with the low-valent Fe(I) center. On the contrary, the nitrogen-based anionic Bopa ligand renders the $\mathrm{Fe}(\mathrm{I})$ center highly reactive such that species $\mathbf{1 6}$ cannot be observed or isolated.

The mechanism of this Fe catalysis might also be compared with that of alkyl-alkyl Kumada coupling catalyzed by the nickel pincer complex, Nickamine. ${ }^{25}$ There are a number of similarities. In both systems, transmetalation precedes oxidative addition, and the oxidative addition follows a bimetallic radical pathway. Furthermore, stable organometallic intermediates (Fe(II) Ar or Ni(II) alkyl) each need to be activated by one molecule of Grignard reagent to activate alkyl halide. It is tempting to consider these as common features in Kumada coupling reactions catalyzed by ligated $1^{\text {st }}$ row transition metals, although more systems should be investigated. The Fe and Ni sys- 
tems exhibit significant differences as well. There is a remarkable and surprising change of coordination geometries of the $\mathrm{Fe}$ intermediates in the solid-state. The Fe(III) halide pre-catalyst is 5-coordinate, the $\mathrm{Fe}$ (II) halide catalyst is 6-coordinate with two solvent ligands, and the Fe(II) aryl catalyst is tetrahedral 4-coordinate. It, however, cannot be excluded that in the solution the Fe(II) species will bind additional solvent molecules (e.g., THF) to form an octahedral geometry. In contrast, the Ni catalysts remain $\mathrm{Ni}(\mathrm{II})$ and square-planar. An additional difference is the reactivity of the active species $\left[\mathrm{Fe}(\mathrm{Bopa}-\mathrm{Ph})(\mathrm{Ph})_{2}\right] \mathrm{MgCl}$ and $\left[\mathrm{Ni}\left(\mathrm{N}_{2} \mathrm{~N}\right)(\mathrm{Alkyl})\right](\mathrm{AlkylMgCl})$. In the former, the two phenyl groups are coupled in similar probability with alkyl halide and can be treated as a genuine "ate" complex. In the latter, the original alkyl group is coupled preferentially with alkyl halide, so the second molecule of alkylMgCl is only weakly associated.

\section{Conclusion}

By using a strongly chelating pincer ligand Bopa, we are able to prepare and isolate ligated Fe complexes which are genuine catalysts and intermediates in Fe-catalyzed alkyl-aryl Kumada coupling reactions. The easily accessible $\mathrm{Fe}$ (III) dichloride precatalyst is first reduced by the Grignard reagent to form the $\mathrm{Fe}$ (II) halide catalyst which is transmetalated to form the Fe(II) aryl catalyst. The structural elucidation of the Fe catalysts reveals remarkable geometric changes of the Fe species. Although the Fe(II) aryl catalyst activates alkyl halide to form the alkyl-aryl coupling product, this reaction is too slow to be catalytically relevant. Instead, the Fe(II) aryl catalyst is further transmetalated to form an Fe(II) bis(aryl) "ate" complex which is the true active species for oxidative addition of alkyl halide. This oxidative addition proceeds via a bimetallic and radical pathway in which two Fe(II) aryl species provide one-electron each. The kinetics of the coupling of an alkyl iodide with $\mathrm{PhMgCl}$ shows a $2^{\text {nd }}$ order in catalyst, $1^{\text {st }}$ in Grignard reagent, and $0^{\text {th }}$ order in alkyl iodide. The turnover determining step is transmetalation of $\mathrm{Fe}(\mathrm{II})$ aryl catalyst to form the active "ate" complex, which seems to proceed via a bimetallic intermediate. The mechanisms of Fe-catalyzed coupling reactions are likely ligand-dependent, and the particular mechanism described here is only confirmed for the Fe-Bopa pincer system. However, this comprehensive mechanistic study using well-defined $\mathrm{Fe}$ pincer catalysts should provide significant new insights into the general understanding of Fe-catalyzed coupling reactions of alkyl halides.

\section{Experimental Section}

\section{General method}

All manipulations were carried out under an inert $\mathrm{N}_{2}$ atmosphere using standard Schlenk or glove box techniques. The solvents were purified and dried using a two column solid-state purification system. They were transferred to the glove box in a Strauss-flask without exposure to air. The solvents were stored over molecular sieves ( $3 \AA$ ). Deuterated solvents were purchased from Cambridge Isotope Laboratories, Inc., and were degassed and stored over dried and activated molecular sieves $(3 \AA)$. All other chemicals were purchased from commercial sources and were degassed by standard freeze-pump-thaw procedures prior to use. The Grignard reagents were titrated prior to every use following the literature procedure. ${ }^{45} \mathrm{NMR}$ spectra were recorded on a $400{ }^{1} \mathrm{H}$ NMR chemical shifts were referenced to residual solvent peak as determined relative to TMS $(\delta=0 \mathrm{ppm})$. GC measurement was conducted on a GC equipped with a FI-detector. GC-MS measurements were conducted on a GC equipped with MS and FID-detector. Photochemical experiments were performed in a Rayonet Photochemical Reactor, using Rayonet Photochemical Reactor Lamp of $2537 \AA$ for homogenic irradiation of the samples photochemical reactor. 
The internal temperature was maintained within a $40-60{ }^{\circ} \mathrm{C}$ range with the aid of an integrated mechanical ventilation system. UV/Vis-absorption spectra were recorded with a UV-Vis fiber optic probe connected to a UV-Vis spectrometer.

\section{Synthesis}

The following chemicals were synthesized according to the literature methods: 2,2'-Iminodibenzoic acid, ${ }^{46}$ R-(-)-Phenylglycinol, ${ }^{47}$ 2,2'-Iminodibenzoyl chloride, Bopa-Ph, (Bopa-Ph)Li ${ }^{48} \quad\left[\mathrm{Fe}(\mathrm{Bopa}-\mathrm{Ph}) \mathrm{Cl}_{2}\right] \quad(\mathbf{1}){ }^{23}$ R-(3-bromobutyl)benzene, ${ }^{49}$ tert-Butyl-4-phenylbutaneperoxoate. ${ }^{32}$

Synthesis of [Fe(Bopa-Ph)Cl(THF) $)_{2}$ ] (2). (Bopa-Ph)Li (2.0 g, 1.1 equiv) was dissolved in $10 \mathrm{~mL}$ THF and $\mathrm{FeCl}_{2}(\mathrm{THF})_{1.5}$ (930 mg, 1.0 equiv) was added. The solution was stirred overnight. The solvent was evaporated and the complex was redissolved in toluene and filtered over celite. The filtrate was concentrated and precipitated with pentane. The solid was filtered off and recrystallized from THF/pentane giving red octahedral crystals. The crystals for the x-ray analysis were obtained by diffusing pentane into a THF solution of 2. Yield: $2.6 \mathrm{~g}$ (93\%), red octahedral crystals. Elemental analysis calculated (\%) for $\mathrm{C}_{38} \mathrm{H}_{40} \mathrm{ClFeN}_{3} \mathrm{O}_{2}: \mathrm{C} 65.76, \mathrm{H} \mathrm{5.81,} \mathrm{N} \mathrm{6.05}$; found: C 65.34, H 5.78, N 6.04

Synthesis of [Fe(Bopa-Ph)Ar] (4 and 5). Method A for 4 and 5: 2 (1.0 equiv) was dissolved in $5 \mathrm{~mL}$ of Dioxane and aryl Grignard (1.0 equiv) was added dropwise at r.t. The reaction was stirred for $30 \mathrm{~min}$. The stirring was stopped to precipitate the Mg-salts. The supernatant was slowly filtered over a pad of celite. The solvent was removed and the residue was redissolved in a minimum amount of toluene and filtered slowly over a pad of celite. The resulting solution was precipitated by adding pentane. The formed precipitate was filtered off and washed with pentane. Crystals of 5 were obtained by overlayering a solution of 5 in THF/Dioxane (1:1) with pentane. Yield: 4: 75\%, 5: 86\%. Elemental analysis calculated (\%) for $\mathrm{C}_{37} \mathrm{H}_{31} \mathrm{FeN}_{3} \mathrm{O}_{2}(5)+1.5$ dioxane: $\mathrm{C}$ 69.97, H 5.87, $\mathrm{N}$ 5.69; found: C 69.26, H 5.75, N 5.66

Method B for 4: 1 (798 mg, 1.0 equiv) was dissolved in $50 \mathrm{~mL}$ THF and $10 \mathrm{~mL}$ dioxane were added (the addition of dioxane is crucial to precipitate the formed $\mathrm{MgCl}_{2}$; otherwise part of the complex start to decompose). $1.40 \mathrm{~mL}$ $\mathrm{PhMgCl}$ (1.83 M solution in THF, 1.9 equiv) was added dropwise over an hour. The solids were filtered off over a pad of celite, and the solution was concentrated to about $20 \mathrm{~mL}$ and then precipitated by adding pentane. The solid was filtered off, and redissolved in a minimum amount of benzene, filtered over celite and precipitated by adding pentane. The solid was filtered off and thoroughly washed with pentane. Yield of 4: 43\% Elemental analysis calculated (\%) for $\mathrm{C}_{36} \mathrm{H}_{29} \mathrm{FeN}_{3} \mathrm{O}_{2}$ (4) + 0.5 Dioxane: $\mathrm{C} 71.81, \mathrm{H}$ 5.23, N 6.61; found: C 71.54, H 5.55, N 6.42

\section{General procedure for coupling}

Alkyl halide $(0.5 \mathrm{mmol})$ was dissolved in $3.0 \mathrm{~mL}$ THF and $1.0 \mathrm{~mL}$ of [ $\left.\mathrm{Fe}(\mathrm{Bopa}-\mathrm{Ph}) \mathrm{Cl}_{2}\right]$ stock solution $(25 \mathrm{mM})$ was added. The solution was brought to the corresponding temperature $\left(-40^{\circ} \mathrm{C}\right.$ or room temperature) and $0.33 \mathrm{~mL}$ $\mathrm{PhMgCl}(1.86 \mathrm{M}$ in THF) was added over a time period of $5 \mathrm{~min}$. The reaction mixture was stirred for another 10 minutes and was quenched with water. The solution was acidified with $\mathrm{HCl}(1 \mathrm{M})$ and extracted with $3 \times 20 \mathrm{~mL}$ of $\mathrm{CH}_{2} \mathrm{Cl}_{2}$. The combined organic phases were dried over $\mathrm{Na}_{2} \mathrm{SO}_{4}$ and the solvent was evaporated to dryness. The crude product was purified by column chromatography ( $0 \%$ to $5 \%$ ethyl acetate in hexane).

\section{General procedure for radical-probe experiments}

The bromoalkane $(0.25 \mathrm{mmol})$ and $1(12.5 \mu \mathrm{mol})$ were weighed into a vial and dissolved in THF $(2.0 \mathrm{~mL})$. $\mathrm{PhMgCl}$ in THF $(0.30 \mathrm{mmol})$ were added dropwise over a time period of 5 minutes at room temperature. After addition the solution stirred for another 10 minutes. The solution was quenched with water and further acidified 
with $\mathrm{HCl}(1 \mathrm{M})$ and extracted with $3 \times 20 \mathrm{~mL}$ of $\mathrm{CH}_{2} \mathrm{Cl}_{2}$. The combined organic phases were dried over $\mathrm{Na}_{2} \mathrm{SO}_{4}$ and the solvent was evaporated to dryness.

\section{Reaction of [Fe(Bopa-Ph)Ph] (4) with tert-butyl-4-phenylbutaneperoxoate under UV-irradiation.}

A solution of [Fe(Bopa-Ph) $\mathrm{Ph}](6.44 \mathrm{mM}, 1.0 \mathrm{~mL})$ and dodecane (internal standard) was put in a J. Young-NMR tube and tert-butyl-4-phenylbutaneperoxoate $(5.6 \mathrm{mg}, 23.7 \mu \mathrm{mol})$ was added. The sample was put in a Rayonet Photochemical reactor for $1.5 \mathrm{~h}$. The reaction mixture was quenched with methanol and the coupling products were checked by GC/MS using dodecane as an internal standard (a FI-detector was used for quantification).

\section{General procedure for kinetic studies.}

Initial rate approximation method was used and the measurements were done using catalyst 2 . The determination of the order on Grignard reagent is given as an example. In one experiment 8 reaction solutions were prepared with variable Grignard concentrations. The reactions were performed in a consecutive order to maintain the same reaction and sampling conditions. For each reaction $10 \mathrm{GC}$ samples were prepared. To achieve a constant reaction temperature a slurry of melting ethyl acetate $\left(\mathrm{m} . \mathrm{p} .=-84^{\circ} \mathrm{C}\right)$ was prepared before the experiment. The example given below depicts one single experiment. In order to determine the order of the reaction the mean value of at least three independent experiments was taken. Before the experiment three stock solutions were prepared: Sol.A: $1.0 \mathrm{~mL}$ of $\mathrm{PhMgCl}$ in $\mathrm{THF}(1.85 \mathrm{M})$ were diluted to $5.0 \mathrm{~mL}$ THF solution $(\mathrm{c}=0.37 \mathrm{M})$. Sol.B: (3Iodobutyl)benzene $(289.6 \mathrm{mg}, 1.11 \mathrm{mmol})$ and naphthalene $(60.3 \mathrm{mg}, 0.47 \mathrm{mmol})$ as an internal standard were diluted to $9.0 \mathrm{~mL}$ THF solution $(\mathrm{c}=0.124 \mathrm{M})$. Sol.C: [Fe(Bopa-Ph)Cl(THF) $)_{2}$ ( $\left.43.8 \mathrm{mg}, 63.1 \mu \mathrm{mol}\right)$ were dissolved in $5.0 \mathrm{~mL}$ THF $(\mathrm{c}=12.6 \mathrm{mM})$. Inside the glove box screw vials with a stirring bar were filled with 0.2 , $0.3,0.4,0.5,0.6,0.7,0.8$, and $1.0 \mathrm{~mL}$ of Sol.A, then $1.0 \mathrm{~mL}$ of Sol.B was added. The vials were filled up with THF to a total volume of $2.0 \mathrm{~mL}$. The vials were closed with a rubber septum. $0.5 \mathrm{~mL}$ of Sol.C was put in $1.0 \mathrm{~mL}$ insulin syringes (the tip of the needle was put in a rubber stopper to minimize the exposure to air). The vials were taken out of the glove box and attached to the Schlenk line by piercing a needle through the septum. The following procedure was done consecutively with every reaction vial: The vial was put in the ethyl acetate slurry, and stirred for about 5 minutes (to be sure that the temperature is constant). Then the rubber septum was removed from the vial (while maintaining the nitrogen flow). Sol.C was added at once. An aliquot of $100 \mu \mathrm{L}$ was taken in regular intervals (depending on the concentration of Grignard reagent and hence its reaction rate) and immediately pipetted in a GC vial containing $50 \mu \mathrm{L}$ acetonitrile. The GC vials were then filled with diethyl ether and analyzed by GC (a FI-detector was used for quantification). The yields of the 1,3-diphenylbutane were determined in respect to naphthalene as an internal standard. $\mathrm{n}$ order to determine the reaction rate, the data points (up to $10 \%$ yield) were fitted linear. The reaction rates were then logarithmized, averaged and plotted versus the logarithm of the $\mathrm{PhMgCl}$ concentration.

\section{Computational details}

Geometries of all species were optimized in the gas-phase at the unrestricted M06 $39,40 /$ def2-SVP level using the "Ultrafine" grid in Gaussian09. ${ }^{50}$ The relative energetics of the various spin states of the Fe complexes $\mathbf{4}, \mathbf{1 3}, \mathbf{1 4}$, 15 were confirmed from computations using both the M06 and OPBE functionals. ${ }^{33,51}$ The later functional feature OPTZ exchange, which assists in the accurate reproduction of energies of inorganic complexes with different spin states. ${ }^{52-54}$ The M06/def2-SVP geometries of relevant compounds were then recomputed as single point energies using a density-dependent dispersion correction ${ }^{35-38}$ appended to the PBE0 $0^{33,34}$ functional (PBE0-dDsC) with the triple- $\zeta$ slater-type orbital TZ2P basis set in ADF. ${ }^{55,56}$ Solvation corrections (in THF) employed the continuum 
solvent model for realistic solvents ${ }^{41}$ (COSMO-RS), as implemented in ADF. The minimum energy crossing point of 15 was located using the "MECP Location Program" of Harvey. ${ }^{57}$ The supplemental file Fe_Coupling_CartesianCoords contains the computed Cartesian coordinates of all of the molecules reported in this study.

\section{Acknowledgement}

This work is supported by a starting grant from the European Research Council under the European Community's Seventh Framework Programme (FP7 2007-2013)/ERC Grant agreement no. 257096. MDW acknowledges BFE Curchod and Prof. C. Corminboeuf (EPFL) for insightful discussions. The Laboratory for Computational Molecular Design at EPFL is acknowledged for providing computational resources.

\section{ASSOCIATED CONTENT}

Supporting Information

Additional experimental and computational details and characterization data. This material is available free of charge via the Internet at http://pubs.rsc.org. 


\section{REFERENCES}

(1) Sherry, B. D.; Furstner, A. Acc. Chem. Res. 2008, 41, 1500-1511.

(2) Rudolph, A.; Lautens, M. Angew. Chem., Int. Ed. 2009, 48, 2656-2670.

(3) Furstner, A.; Martin, R. Chem. Lett. 2005, 34, 624-629.

(4) Leitner, A. In Iron Catalysis in Organic Chemistry; Wiley-VCH: Weinheim, 2008, p 147-176.

(5) Bolm, C.; Legros, J.; Le Paih, J.; Zani, L. Chem. Rev. 2004, 104, 6217-6254.

(6) Martin, R.; Furstner, A. Angew. Chem., Int. Ed. 2004, 43, 3955-3957.

(7) Nakamura, M.; Matsuo, K.; Ito, S.; Nakamura, E. J. Am. Chem. Soc. 2004, 126, 3686-3687.

(8) Furstner, A.; Martin, R.; Krause, H.; Seidel, G.; Goddard, R.; Lehmann, C. W. J. Am. Chem. Soc. 2008, 130, 8773-8787.

(9) Ghorai, S. K.; Jin, M.; Hatakeyama, T.; Nakamura, M. Org. Lett. 2012, 14, 1066-1069.

(10) Nagano, T.; Hayashi, T. Org. Lett. 2004, 6, 1297-1299.

(11) Cahiez, G.; Habiak, V.; Duplais, C.; Moyeux, A. Angew. Chem., Int. Ed. 2007, 46, 4364-4366.

(12) Czaplik, W. M.; Mayer, M.; Jacobi von Wangelin, A. Angew. Chem., Int. Ed. 2009, 48, 607-610.

(13) Bedford, R. B.; Betham, M.; Bruce, D. W.; Danopoulos, A. A.; Frost, R. M.; Hird, M. J. Org. Chem. 2006, 71, 1104-1110.

(14) Bedford, R. B.; Betham, M.; Bruce, D. W.; Davis, S. A.; Frost, R. M.; Hird, M. Chem. Commun. 2006, 1398-1400.

(15) Furstner, A.; Krause, H.; Lehmann, C. W. Angew. Chem., Int. Ed. 2006, 45, 440-444.

(16) Al-Afyouni, M. H.; Fillman, K. L.; Brennessel, W. W.; Neidig, M. L. J. Am. Chem. Soc. 2014, 136, 15457-15460.

(17) Noda, D.; Sunada, Y.; Hatakeyama, T.; Nakamura, M.; Nagashima, H. J. Am. Chem. Soc. 2009, 131, 6078-6079.

(18) Bedford, R. B.; Brenner, P. B.; Carter, E.; Cogswell, P. M.; Haddow, M. F.; Harvey, J. N.; Murphy, D. M.; Nunn, J.; Woodall, C. H. Angew. Chem., Int. Ed. 2014, 53, 1804-1808.

(19) Adams, C. J.; Bedford, R. B.; Carter, E.; Gower, N. J.; Haddow, M. F.; Harvey, J. N.; Huwe, M.; Cartes, M. A.; Mansell, S. M.; Mendoza, C.; Murphy, D. M.; Neeve, E. C.; Nunn, J. J. Am. Chem. Soc. 2012, 134, 10333-10336.

(20) Bedford, R. B.; Carter, E.; Cogswell, P. M.; Gower, N. J.; Haddow, M. F.; Harvey, J. N.; Murphy, D. M.; Neeve, E. C.; Nunn, J. Angew. Chem., Int. Ed. 2013, 52, 1285-1288.

(21) Guisan-Ceinos, M.; Tato, F.; Bunuel, E.; Calle, P.; Cardenas, D. J. Chem. Sci. 2013, 4, 1098-1104.

(22) Inagaki, T.; Ito, A.; Ito, J.; Nishiyama, H. Angew. Chem., Int. Ed. 2010, 49, 9384-9387.

(23) Inagaki, T.; Phong, L. T.; Furuta, A.; Ito, J.; Nishiyama, H. Chem.-Eur. J. 2010, 16, 3090-3096.

(24) See the supporting information.

(25) Breitenfeld, J.; Ruiz, J.; Wodrich, M. D.; Hu, X. L. J. Am. Chem. Soc. 2013, 135, 12004-12012.

(26) Hedstrom, A.; Bollmann, U.; Bravidor, J.; Norrby, P.-O. Chem.-Eur. J. 2011, 17, 11991-11993.

(27) Kinney, R. J.; Jones, W. D.; Bergman, R. G. J. Am. Chem. Soc. 1978, 100, 635-637.

(28) Kinney, R. J.; Jones, W. D.; Bergman, R. G. J. Am. Chem. Soc. 1978, 100, 7902-7915.

(29) Biswas, S.; Weix, D. J. J. Am. Chem. Soc. 2013, 135, 16192-16197.

(30) Breitenfeld, J.; Wodrich, M. D.; Hu, X. L. Organometallics 2014, 33, 5708-5715.

(31) Fossey, J. S.; Lefort, D.; Sorba, J. Free radicals in organic chemistry; Wiley, 1995.

(32) Rueda-Becerril, M.; Sazepin, C. C.; Leung, J. C. T.; Okbinoglu, T.; Kennepohl, P.; Paquin, J. F.; Sammis, G. M. J. Am. Chem. Soc. 2012, 134, 4026-4029.

(33) Perdew, J. P.; Burke, K.; Ernzerhof, M. Phys. Rev. Lett. 1996, 77, 3865-3868.

(34) Adamo, C.; Barone, V. J. Chem. Phys. 1999, 110, 6158-6170.

(35) Steinmann, S. N.; Corminboeuf, C. J. Chem. Theory Comp. 2010, 6, 1990-2001.

(36) Steinmann, S. N.; Corminboeuf, C. J. Chem. Theory Comp. 2011, 7, 3567-3577.

(37) Steinmann, S. N.; Corminboeuf, C. J. Chem. Phys. 2011, 134.

(38) Steinmann, S. N.; Corminboeuf, C. Chimia 2011, 65, 240-244. 
(39) Zhao, Y.; Truhlar, D. G. Theor. Chem. Acc. 2008, 120, 215-241.

(40) Zhao, Y.; Truhlar, D. G. Acc. Chem. Res. 2008, 41, 157-167.

(41) Klamt, A. WIREs Comput. Mol. Sci. 2011, 1, 699-709.

(42) Muller, H.; Seidel, W.; Gorls, H. J. Organomet. Chem. 1993, 445, 133-136.

(43) Klose, A.; Solari, E.; Floriani, C.; Chiesivilla, A.; Rizzoli, C.; Re, N. J. Am. Chem. Soc. 1994, 116, 9123-9135.

(44) Ni, C. B.; Power, P. P. Organometallics 2009, 28, 6541-6545.

(45) Love, B. E.; Jones, E. G. J. Org. Chem. 1999, 64, 3755-3756.

(46) Paul, A.; Ladame, S. Org. Lett. 2009, 11, 4894-4897.

(47) McKennon, M. J.; Meyers, A. I.; Drauz, K.; Schwarm, M. J. Org. Chem. 1993, 58, 3568-3571.

(48) Csok, Z.; Vechorkin, O.; Harkins, S. B.; Scopelliti, R.; Hu, X. L. J. Am. Chem. Soc. 2008, 130, 8156-8157.

(49) Crosignani, S.; Nadal, B.; Li, Z. N.; Linclau, B. Chem. Commun. 2003, 260-261.

(50) Frisch, M. J.; Trucks, G. W.; Schlegel, H. B.; Scuseria, G. E.; Robb, M. A.; Cheeseman, J. R.; Scalmani, G.; Barone, V.; Mennucci, B.; Petersson, G. A.; Nakatsuji, H.; Caricato, M.; Li, X.; Hratchian, H. P.; Izmaylov, A. F.; Bloino, J.; Zheng, G.; Sonnenberg, J. L.; Hada, M.; Ehara, M.; Toyota, K.; Fukuda, R.; Hasegawa, J.; Ishida, M.; Nakajima, T.; Honda, Y.; Kitao, O.; Nakai, H.; Vreven, T.; Montgomery, J., J. A.; Peralta, J. E.; Ogliaro, F.; Bearpark, M.; Heyd, J. J.; Brothers, E.; Kudin, K. N.; Staroverov, V. N.; Kobayashi, R.; Normand, J.; Raghavachari, K.; Rendell, A.; Burant, J. C.; Iyengar, S. S.; Tomasi, J.; Cossi, M.; Rega, N.; Millam, M. J.; Klene, M.; Knox, J. E.; Cross, J. B.; Bakken, V.; Adamo, C.; Jaramillo, J.; Gomperts, R.; Stratmann, R. E.; Yazyev, O.; Austin, A. J.; Cammi, R.; Pomelli, C.; Ochterski, J. W.; Martin, R. L.; Morokuma, K.; Zakrzewski, V. G.; Voth, G. A.; Salvador, P.; Dannenberg, J. J.; Dapprich, S.; Daniels, A. D.; Farkas, O.; Foresman, J. B.; Ortiz, J. V.; Cioslowski, J.; Fox, D. J.; Gaussian, Inc.: Wallingford, CT, 2009.

(51) Handy, N. C.; Cohen, A. J. Molecular Physics 2001, 99, 403-412.

(52) Conradie, J.; Ghosh, A. J. Phys. Chem. B 2007, 111, 12621-12624.

(53) Rotzinger, F. P. J. Chem. Theory Comp. 2009, 5, 1061-1067.

(54) Curchod, B. F. E.; Rotzinger, F. P. Inorg. Chem. 2011, 50, 8728-8740.

(55) Guerra, C. F.; Snijders, J. G.; te Velde, G.; Baerends, E. J. Theor. Chem. Acc. 1998, 99, $391-403$.

(56) te Velde, G.; Bickelhaupt, F. M.; Baerends, E. J.; Guerra, C. F.; Van Gisbergen, S. J. A.; Snijders, J. G.; Ziegler, T. J. Comput. Chem. 2001, 22, 931-967.

(57) Harvey, J. N.; Aschi, M.; Schwarz, H.; Koch, W. Theor. Chem. Acc. 1998, 99, 95-99. 